\title{
A dor que deveras sente
}

\section{Carlos Morais JOSÉ}

"De la musique avant toute chose"

Haverá uma frase de Borges que nos remete para o devaneio de na poesia se encontrarem contidas a música e a pintura, pois a sucessão de palavras - para além das ideias - conteria ritmos, melodias e imagens. Deixando, por ora, de lado a vertente contemplativa e considerando unicamente a música, não será difícil atribuir o carácter encantatório do fluir poético à existência de uma musicalidade no poema, seja ela derivada da sonoridade das palavras ou do modo como se entrelaçam, para depois se sucederem as imagens e os conceitos.

1 carlosmoraisjose@gmail.com 
Existe na poesia um efeito vibratório, musical, onde reside, se não o seu principal pólo de interesse, pelo menos a fonte de parte considerável do seu fascínio. "Os estímulos visuais", refere Ester de Lemos, "não escapam tão facilmente à vigilância da razão, não são tão facilmente encarados em si mesmos como os estímulos auditivos, sobretudo os musicais" (1956, p. 30). Se a música escapa à vigilância da razão, ela será o meio excelente para arrebatar, para suster essa poesia que "eleva cada indivíduo através de uma ligação específica com o todo restante" (Novalis, 2009, p. 121).

Este carácter sintético da poesia, em grande parte ancorado nessa musicalidade, não deverá ser entendido como referido à dialéctica, que prevê um momento de negação, mas a um mero gesto de apropriação criacionista, capaz de proporcionar polaridades outras e sistemas de leitura, o que equivale a dizer reinventar universos e abrir uma miríade de possibilidades à expressão da vida.

A sintese, na dialéctica, exprime, afinal, o culminar do processo de aculturação; no criacionismo, a função da negação, fundamental na construção da identidade, só estará presente na expressão poética como condição de sinceridade do media, como se pretendesse operar uma regressão a um estado anterior onde a graça da criança (das três metamorfoses de Nietzsche/Zaratrusta) lhe permite apoderar-se do mundo num golpe. Não se tratará, contudo, de uma regressão propriamente dita mas de uma reaquisição - a saudade é do futuro.

Se, para Rousseau, a primeira linguagem era poética, tal seria no sentido em que uma palavra dessa primitiva língua encerraria muito mais sentidos que o seu significado literal (ou que este não existiria e muitos significados estariam contidos numa palavra só) e os homens de antanho falariam basicamente por metáforas, abarcando assim mais do mundo do que eles próprios poderiam compreender, sendo a Língua o repositório de um sa- 
ber que os próprios indivíduos que a falavam apenas entenderiam parcialmente.

A poesia inscreve-se numa ânsia de apropriação do mundo e dos seus sentidos ocultos, num claro sentir filosófico em que, para além da vibração musical (mas também em ela), o poema expressa uma visão, eventualmente, o esboço ou o castelo final de uma qualquer metafísica.

É com o primeiro Romantismo que poeta e poesia exacerbam essa ânsia, assumindo o conceito poético que elevará o "homem acima de si mesmo". Trata-se, no dizer de Novalis (2009), de uma poesia "transcendental", que é "mesclada de filosofia e poesia", e que prefigura a dissolução dos sistemas filosóficos, na medida em que, "se o filósofo ordena tudo, coloca tudo, então o poeta dissolveria todos os elos. As suas palavras não são signos universais - são sons - palavras mágicas, que movem belos grupos em torno de si". Novalis remataria: "Quando mais poético, mais verdadeiro".

Parece então que, com o Iluminismo, o poeta visa a ultrapassar o mero papel mediador do xamã para aspirar a ser ele mesmo - através dessa transcendentalidade que lhe proporciona o pensamento filosófico e mesmo a ciência - uma fonte de permanente problematização, expressão radical da vida mas também das volutas do espírito, sem abdicar também do modo - mágico - como eventualmente recuperará alguns restos dessa linguagem primordial, onde se rebatiam os mistérios do mundo e das coisas.

\section{Pessanha e as "nobres especulações do espírito"}

Sem deter o exclusivo ou sequer a preponderância, poesia e filosofia particularmente se entrelaçam no espaço da Língua Portuguesa, por razões que talvez passem pelo defeito da segun- 
da e o excesso da primeira. Após o milagre grego, raramente o Sul produziu um assertivo pensamento lógico, mas as preocupações metafísicas, lidas através dos penetrantes filtros da experiência do mundo e de particulares sensibilidades, cedo se imiscuíram em temáticas versejadas. Já em Camões, para não irmos mais atrás, ao vate, ao cantor épico, se sobrepunha o homem dilacerado pela dúvida, onde o recurso à mitologia soa - além da epocalidade renascentista - ao desespero de constatar uma diversidade percorrida, revivida, recebida e, portanto, a intuição de um mundo desencantado.

Na segunda metade do século XIX, a presença cimeira de Antero de Quental - o que “ensinou a pensar em ritmo; descobriu-nos a verdade de que o ser imbecil não é indispensável a um poeta" (Fernando Pessoa) -, com certeza deu um tom definitivamente filosófico à expressão da poesia lusófona e talvez poético à filosofia pensada em português. As crises, civilizacional na Europa e muito específica em Portugal, na sequência do Ultimatum britânico, eram demasiado profundas e dolorosas para que os poetas se limitassem aos devaneios dos salões, às rimas de ocasião, enfim às actividades dos que Pessanha define como "essa legião de poeta mínimos, cuja pobre musa toda a sua fecundidade esgota na concepção de cem páginas de lirismo".

Como explica Gustavo Rubim, Camilo Pessanha critica a poesia como "uma expressão directa dos sentimentos, das sensações ou da experiência vivida do poeta e opõe-lhe uma concepção mais abstracta que inscreve o discurso poético no campo das "especulações do espírito"'. Ora para sustentar a filosofia no discurso poético, para lhe garantir o carácter especulativo, implica, como diz o autor de Experiência da Alucinação, "uma certa dimensão impessoal" (Rubim, 1993, p. 142). Ou seja, o 
que Fernando Pessoa já exprimia, quando escreveu este revelador apontamento:

A cada um de só três poetas, no Portugal dos séculos XIX a XX, se pode aplicar o nome de "Mestre". São eles Antero de Quental, Cesário Verde e Camilo Pessanha. [...] O terceiro ensinou a sentir veladamente*; descobriu-nos a verdade de que para ser poeta não é mister trazer o coração nas mãos, senão que basta trazer nelas os simples sonhos dele. Estas palavras que não são nada bastam para apresentar a obra do enorme poeta Camilo Pessanha.

O mais, que é tudo, é Camilo Pessanha.

Este "trazer nas mãos os sonhos do coração" implicará um duplo distanciamento: uma consciência primeira que, se bem que sob o filtro da sensibilidade, exige a exterioridade; e uma exterioridade que permite a reflexão distanciada. $\mathrm{O}$ poeta adquire esse distanciamento em relação a si mesmo (ao lirismo óbvio) e à possibilidade de contemplar (teorizar) o que detém agora nas mãos, operando uma espécie de processo alquímico de destilação, decantação e, finalmente, sedimentação - de sensações, sentimentos e ideias - nas palavras finais do poema. Isso é de tal modo presente em Pessanha que, mesmo quando produzia "os seus poemas por uma premente necessidade espiritual", fazia-o "numa atitude eminentemente intelectual [...] vivendo e revivendo o sentir dos momentos de concepção poética" (Dias Miguel, 1956, p. 185).

É então a poesia o canto desses sonhos do coração? O que são eles? Parece-nos que Pessoa se refere, quase falando numa linguagem gémea da de Pessanha, a um processo poético. 
Curiosamente (e tal não deverá passar de uma coincidência), no pensamento tradicional chinês, seja ele confucionista ou daoísta, o coração (xin) é a entidade onde residem as emoções, os desejos, os sentimentos, o pensamento e a moral, ou seja, ali se entrelaça toda a fenomenologia da existência interna dos seres humanos. Se entendermos coração nesse sentido, teremos então o indivíduo e todos as seus rizomas culturais nas mãos.

Mas Pessanha, por outro lado, entregava-se "ao trabalho do aperfeiçoamento da expressão, preocupado até à angústia com o sortilégio e a magia verbal, condensando e polindo de tal modo, que muitas vezes obscurecia quase totalmente o sentido biográfico e directo que tinham essas poesias", nas palavras de António Dias Miguel (1956). Assim se revelam a existência de uma matriz filosófica e uma exigência de distanciamento biográfico, a par com a demanda extrema da musicalidade.

Seguindo essas referências, parece inegável que a reflexão filosófica ocupa um lugar fundamental na poesia de Camilo Pessanha. Ainda que nem sempre explícita, a sua concepção do mundo constituiu, talvez de forma dolorosa, uma das principais episteme onde a sua poesia lançou raízes e a partir da qual se desenvolveu.

\section{A pergunta e o gelo}

Já em 1887, no poema "Soneto de Gelo", o poeta explicitava algumas das preocupações derivadas do seu dispositivo ontológico:

Eu mesmo quero a fé, e não a tenho,

- Um resto de batel - quisera um lenho,

Para não afundir na treva imensa, 
O Deus, o mesmo Deus que te fez crente...

Nem saibas que esse Deus omnipotente

Foi quem arrebatou a minha crença.

Ou seja: a ausência da fé, uma existência num mundo sem Deus e, consequentemente, a morte como fronteira de dissolução do indivíduo. O poeta quisera uma pequena prova, ainda que só "um lenho", de "um resto de batel" (a barca, baraka - animal fantástico, montada de Abraão e Maomé, que na mitologia islâmica opera a comunicação entre dois mundos), algo onde se suster, que o não deixe "afundir na treva imensa" de um universo vazio de sentidos divinos ou de quaisquer outras satisfatórias respostas.

É precisamente essa "treva imensa", o segredo insondável, que provoca no poeta o início de uma profunda dor metafísica, quase revolta contra a divindade pelo seu silêncio/inexistência e sua consequente falta de fé. Se foi Deus "quem arrebatou a minha crença", é porque o estado de descrença é anterior ao próprio advento do raciocínio científico-filosófico ou da intromissão da cultura. É certo que a falta de fé surgirá também como decorrente do próprio ZeitGeist, da posição do poeta num dado momento civilizacional. É a religião na qual foi educado, as relações familiares, a escola frequentada, o valor atribuído ao conhecimento científico, a sociedade emergente, enfim, o conjunto global de valores e procedimentos que constituem uma Cultura num determinado momento da História, que tornavam problemática a existência de Deus. Mas Pessanha parece afirmar que sente a sua descrença, de algum modo, anterior, constitutiva e fatal, porque lhe foi arrebatada por Deus, o que não deixa de exalar uma paradoxal ironia.

A extinção da crença resultará como anteriormente resultava a sua afirmação: sem que o sujeito nela tenha uma real 
intervenção. Pessanha assume neste poema o seu ateísmo como condição (dolorosa) e não como decisão consciente. Até porque o novo universo, dessacralizado, não lhe fornece respostas. Simplesmente, efemeramente o admite, na sua fria indiferença, sem proporcionar qualquer consolo às angústias fundacionais dos humanos.

O poeta refere esse mal-estar matricial no poema "Estátua":

Cansei-me de tentar o teu segredo:

No teu olhar sem cor, - frio escalpelo,

O meu olhar quebrei, a debatê-lo,

Como a onda na crista dum rochedo.

Segredo dessa alma e meu degredo

E minha obsessão! Para bebê-lo

Fui teu lábio oscular, num pesadelo,

Por noites de pavor, cheio de medo.

E o meu ósculo ardente, alucinado,

Esfriou sobre mármore correcto

Desse entreaberto lábio gelado:

Desse lábio de mármore, discreto,

Severo como um túmulo fechado,

Sereno como um pélago quieto.

O cansaço de procurar respostas no olhar - acto que remete para a contemplação, a teoria - dá lugar à ousadia do beijo - acto amoroso, a poesia. No primeiro caso, a contemplação esbarra e quebra-se "como a onda na crista de um rochedo". No 
segundo, produz-se um esfriamento do que era "ardente, alucinado". Ou seja, nem a razão consegue penetrar o insondável; nem um extremo desejo e uma vitalidade transbordante obtêm outro resultado que não seja a sua própria dissolução. Em ambos os casos, sobrevém uma existência assombrada pelo silêncio.

Emana, de facto, deste poema uma sensação de horror perante um universo feito estátua, em cuja indiferença nem Razão nem Vida penetram. Estátua porque, se bem que gelado e silencioso, de olhar sem cor como as estátuas gregas, ainda assim, tal como a escultura clássica, o universo não deixa de exibir uma certa ordem e exalar uma profunda beleza. Tal acentua o sofrimento do poeta perante a impossibilidade de - não de o conhecer - mas de beber esse segredo. Não serão os conhecimentos científicos, racionais, que trariam satisfação a Camilo Pessanha, pois estes nem de perto pretendem responder às questões que o habitam. Mas, mesmo face às suas ousadias, de pesadelo, nada acontece a não ser o esfriamento perante a gravitas de um "túmulo fechado" ou de um "pélago quieto".

Pessanha habita um universo novo, que a ciência descreve através das teorias quânticas, do princípio da incerteza, da transformação sucessiva de matéria em energia e de energia em matéria, em que a própria matéria não é mais que uma vibração ou ondulação, obediente a ritmos misteriosos, desconhecidos mas dessacralizados.

Não será também o uno conceito de Vontade, de Schopenhauer - como tem sido repetidamente afirmado por uma ligação rápida ao dito pessimismo do alemão -, que aqui estará em jogo. Não existe uma Vontade (conceito eivado de metafísica), mas um palimpsesto de forças, de energias, de vibrações, num universo em que as formas se limitam a uma existência efémera como no poema "Imagens que passais pela retina dos meus olhos / Porque 
não vos fixais?”, em que tudo é transitório e de sentidos vagos. Os "olhos pagãos" somente vêem os "sucessivos desertos". E nem a sua presença deixará qualquer rasto: "Fica sequer, sombra de minhas mãos".

No lugar de Deus não existirá nada, sequer faz sentido o panteísmo de Espinosa. A ideia de um ser divino, antropomórfico ou disseminado, dará lugar a esse resfolgar contínuo de todas as coisas, essa dimensão pulsante que permite supor a existência de um ritmo primordial, incessante, inesgotável, sem face nem propósito, sem leis morais, mera energia e mera matéria, em permanente metamorfose, como o poeta sussurra ainda no seu leito de morte, à laia de despedida: "Tudo podridão... tudo matéria..." E podridão, o leitor do Octave Mirbeau de "O Jardim dos Suplícios", novela passada em Cantão no século XIX, que Pessanha certamente era, sabe que significa metamorfose.

Num plano mais pessoal, é a ausência de uma consciência divina que torna fútil a crença num destino, dando ao indivíduo a sensação solitária de à toa marear na vida, tornando-a também a ela fútil e levando à invocação da morte como acto estético último, no sentido borgesiano da iminência de uma revelação que não se produzirá.

Enfim, levantou ferro.

Com os lenços adeus, vai partir o navio.

Longe das pedras más do meu desterro

Ondas azuis do oceano, submergi-o.

Que eu, desde a partida,

Não sei onde vou.

Roteiro da vida

Quem é que o traçou? 
A sensação de inutilidade da vida ("Foi um dia de inúteis agonias"... "Floriram por engano as rosas bravas...") percorre a obra de Pessanha. A vivência num mundo desencantado, sublinhada pela decadência do país, estriba-se numa ontologia melancólica, onde a aura materialista acaba por ser, em confronto com a sensibilidade do poeta, fonte de uma inextirpável dor.

Camilo Pessanha será um daqueles primeiros homens a ter nascido no mundo de um Deus morto (Nietzsche), mas onde a estrutura religiosa se encontra profundamente imiscuída na Cultura e mantém a sua influência noutros domínios que não o filosófico. Por exemplo, nessa linha, Michel Onfray, no seu Tratado de Ateologia, classifica de ateísmo cristão o pensamento dos homens oitocentistas que não acreditam na existência de Deus, mas cuja moral se rege pelos valores do cristianismo.

No caso de Pessanha - também porque a sua poesia mergulha "as suas raízes no húmus natal" - existirá, não uma moral cristã, mas uma estética primeva que não dispensa uma concepção divina, um plano do mundo. É, sobretudo, em termos estéticos, imagéticos até, com todas as suas consequências, que esses arquétipos assombram Pessanha. Ele recorre aos mitemas da sua cultura, claramente perturbantes, para exprimir o seu desvanecimento no mundo contemporâneo e também na sua própria sensibilidade. Tal procedimento é recorrente quando o poeta se refere, por exemplo, a figuras femininas, segregando imagens como "Magra figura de vitral...", "Madalena, cabelos de rastos...", de nítida influência religiosa ou, num registo mais rural, mas igualmente irreal: a alma de sua mãe, pela neve, a mendigar à porta dos casais.

Repare-se ainda no poema "Transfiguração": 
Mulher forte, remiu-me a tua prece:

Penitente, pagão, bem lusitano

Ergo os braços ao céu quando anoitece.

Judas divaga, em espiras de pecado

Eis-me o Verbo de Deus, sacramentado

No rebuço dum capote alentejano.

A mulher (origem, cultura) fica como repositório da crença, que eventualmente, à la Pascal, o redimirá. Mas ele é Judas (traidor, em pecado) e, mesmo quando poeta, expressão divina, "sacramentado", acaba rebaixado à banal, prosaica, desencantada condição de existência "no rebuço dum capote alentejano".

\section{Fusão ou barbárie}

Uma das consequências principais de um universo dessacralizado é o surgimento da morte como espaço de dissolução do indivíduo. Deus existiu moribundo na poesia do século XIX, até encontrar a sua mais desesperada e última expressão no satanismo, que precedeu o nosso poeta. Tais caminhos mostraram ser becos sem saída, meras expressões contingentes de um problema que cavava mais profundo que uma inversão, na qual, afinal, se declarava um amor supremo edipianizado.

E não seria por aí que Camilo caminharia. Como refere Rubim (1993), a partir da crítica do poeta ao livro Flores de Coral, de Alberto Osório de Castro, nele a vida surge como "uma consequência lógica" da morte, a vida significa a morte, uma não é a negação da outra. "De que havia pois de lamentar-se, ou contra o que havia, pois, de insurgir-se, se a morte é, em relação à vida, não só o termo fatal, mas também a consequência lógica?”. 
Contudo, Pessanha não deixa de considerar a morte como algo de fatal, a par com uma consequência lógica. Daqui se entende a concepção da vida - apenas porque no humano existe à partida o conhecimento antecipado do fim - como fatalidade, embora esteja ausente o destino. O que parece aconchegar tal concepção da morte como dissolução do indivíduo, em que esta não passa de uma "consequência lógica da vida", parece ser um desejo último de fusão com o Cosmos, finalmente de participação total, expurgadas que serão a consciência e a dor.

Recortes vivos das areias,

Tomai o meu corpo e abride-lhe as veias...

O meu sangue entornai-o,

Difundi-o sob o rútilo sol [...].

Só o meu crânio, fique,

Rolando, insepulto no areal,

Ao abandono do simoun

Que o sol e o sal o purifique.

A morte será uma porta para a integração total no universo, integração que não será a de uma alma una mas da matéria que se transforma, de um corpo que se desfaz: "Róseas unhinhas que a maré partira... / Dentinhos que o vaivém desgastara... / Conchas, pedrinhas, pedacinhos de ossos..." é o que sobra de uma vida e da "fúlgida visão, linda mentira!". Poderá ser correcto afirmar que a biografia infantil do poeta, as suas desilusões amorosas e mesmo a sua frágil saúde terão sido razões importante para conferir à dor um lugar de relevância nos seus poemas. Mas creio que, aquém e além das referências biográficas, fará sentido outorgar a essa dor metafísica - consequência da cons- 
ciência da inexistência de Deus, do indivíduo após a morte e do Destino - um papel central na obra do poeta de Clepsidra.

\section{A dor que deveras sente}

De tal modo a questão da dor é central na poesia de Camilo Pessanha que o poeta a transforma em energia necessária, como se ela fosse o único instrumento que permitiria uma visão mais profunda do universo e, de um modo quase perverso, justificasse a existência humana: uma espécie de Sofro, logo existo, na medida em que seria um garante de Ser.

Tenho sonhos cruéis: n’alma doente

Sinto um vago receio prematuro.

Vou a medo na aresta do futuro,

Embebido em saudades do presente...

Saudades desta dor que em vão procuro

Do peito afugentar bem rudemente,

Devendo ao desmaiar sobre o poente,

Cobrir-me o coração dum véu escuro!...

Porque a dor, esta falta de harmonia, Toda a luz desgrenhada que alumia

As almas doidamente, o céu de agora,

Sem ela o coração é quase nada:

- Um sol onde expirasse a madrugada,

Porque é só madrugada quando chora. 
Sem a dor, o coração, os tais sonhos, "é quase nada". São as lágrimas que justificam a madrugada e sem elas o sol não seria sol, nele se extinguiria o que ele próprio proporciona. A importância atribuída à falta de harmonia remete para a frase de Rimbaud: "Finalmente, acabei por considerar sagrada a desordem do meu espírito". No caso do poeta português, essa desordem é fruto da dor, mas é também fonte de iluminação, de uma percepção outra do mundo, como se fora um método poético de absorção mais intensa das coisas. Este poema é de 1888. Mais tarde, o poeta acabaria por rever essa posição como adiante demonstraremos.

Ora a questão da dor fora colocada no debate filosófico, entre outros, por Soren Kierkegaard e por Nietzsche, que, na sua Genealogia da moral, a refere como a grande criadora de memória. O filósofo alemão evoca os grandes espectáculos públicos da dor: as matanças, as carnificinas, as execuções públicas e a tortura, a que a Humanidade tem paulatinamente assistido e cuja função, afirma, é precisamente a criação de uma memória; a dor como uma terrível mnemotécnica, que passa mesmo, em certas sociedades, por rituais extremos e pela inscrição dos corpos.

Num plano individual, a dor também proporciona a memória e demarca os limites de acção dos indivíduos, mas a sua persistência, nomeadamente de uma dor metafísica, impele o sujeito para a reflexão filosófica e - pretenderão alguns - estende o campo de percepção a outras realidades. Tal fará, em Pessanha, que a dor seja invocada: "Saudades desta dor que em vão procuro/ Do peito afugentar bem rudemente". Repare-se no paradoxo: sente-se a falta (heurística) de uma dor que se pretende eliminar, porque ela é "a luz desgrenhada que alumia as almas" e o "céu d'agora". Ou seja, a dor é ainda o que permite, no caos que desencadeia, um determinado conhecimento de si próprio e a intuição do universo. 
Veja-se o exemplo do poema "Branco e Vermelho", no qual a dor se transmuta em luz, em lúcida febre e proporciona a visão, a contemplação do mundo. E é toda uma humanidade agrilhoada que o poeta nos descreve, atravessando um mundo deserto, futilmente explorada e temente de um castigo, seres viventes nos charcos do medo, que só a morte liberta do sofrimento.

A dor induz o poeta a um estado de luminosidade/alucinação que lhe proporciona a visão da humanidade que desfila, açoitada ao ritmo dos seus versos. E que humanidade é essa? Um grande painel de sofrimento, de desconforto metafísico e também produto do crime cometido desde o alvorecer da História: a exploração do homem pelo homem.

Claro que neste poema existem outros cambiantes, outros caminhos interpretativos, nomeadamente (uma vez mais) para quem se quiser referir a conhecimentos esotéricos e à importância do maniqueísmo (a oposição luz/trevas) no pensamento templário e maçónico, sabida que é a filiação de Pessanha à maçonaria. Contudo, cremos que esta filiação, longe de ser religiosa, passava precisamente pela recusa da Igreja e por uma tendência de fraternidade social. É sabido em Macau que a loja a que Pessanha pertencia não tinha um carácter teísta, bem pelo contrário. Dela fizeram parte conhecidos ateus e republicanos.

\section{Alma lânguida e inerme}

À medida que em Macau Pessanha vai adensando os seus contactos com o pensamento chinês, podemos vislumbrar nos seus poemas alguns pontos de contacto com a tradição oriental, nomeadamente eventuais influências daoistas. De facto, a concepção de um mundo heraclitiano, em permanente movimento, não andará muito longe da ontologia proposta pelo 
pensamento daoista, mas será sobretudo o retorno à pureza original, que todo o pensamento clássico chinês prescreve, que encontra nos daoistas um método que nos surge como próximo de certos versos do nosso poeta.

Para o sábio daoísta, deve o homem retirar-se do mundo, afastar-se para o ventre da terra onde, no silêncio, num processo de metamorfoses, comparável ao de uma crisálida, se transformará no Feto Imortal. O daoista alimentar-se-á na sua gruta, sugando as estalactites, como se fossem os seios da Terra.

Pessanha abre precisamente a "Clepsidra" como o famoso poema "Inscrição":

Eu vi a luz em um país perdido.

A minha alma é lânguida e inerme.

Ó! Quem pudesse deslizar sem ruído!

No chão sumir-se, como faz um verme...

Ou mais à frente no mesmo volume:

Porque o melhor, enfim,

É não ouvir nem ver...

Passarem sobre mim

E nada me doer!

- Sorrindo interiormente,

Co'as pálpebras cerradas,

Às águas da torrente

Já tão longe passadas. -

Rixas, tumultos, lutas,

Não me fazerem dano...

Alheio às vãs labutas,

Às estações do ano. 
Passar o estio, o outono,

A poda, a cava, e a redra,

$\mathrm{E}$ eu dormindo um sono

Debaixo duma pedra.

$[\ldots]$

E eu sob a terra firme,

Compacta, recalcada,

Muito quietinho. A rir-me

De não me doer nada.

Ora não se trata aqui da morte mas de atingir um estado outro de consciência, em que a fusão com a Terra, que um psicanalista poderia atribuir a um desejo de fusão com a mãe, seria o passo principal para conseguir um determinado tipo de repouso, que eliminaria a dor.

Gaston Bachelard, curiosamente no mesmo livro em que refere Lúcio Pinheiro dos Santos, um filósofo amigo do poeta de Macau, entende

[...] o repouso como um dos elementos do devir", que se inscreve no "cerne do ser, que devemos mesmo senti-lo no fundo mesmo do nosso ser, ao nível da realidade temporal sobre a qual se apoiam a nossa consciência e a nossa pessoa. [...] Que cada um, à sua maneira, se liberte das excitações de circunstância que o põem fora de si. [...] o ser libertar-se-á de um impulso vital que o afasta para longe dos objectivos individuais, que se desgasta em actuações imitadas. [...] A consciência pura aparecer-nos-á como uma potência de espera e vigia, como uma liberdade e uma vontade de nada fazer. (BACHELARD, 2006, V-VI) 
Estamos então perante uma espécie de quietismo como panaceia para a dor, fonte de iluminação e, no sentido referido por Gustavo Rubim, de alucinação, na medida em que a percepção do mundo se altera, se refina, se torna rítmica através da escuta aproximada do pulsar do pensamento e da própria matéria. Também nessa crisálida emerge, finalmente, um fio de voz, plena de consciência e de musicalidade, que dará origem ao poema. Não se trata, portanto, de um desejo de morte mas de obter um lugar excelso de compreensão do mundo que passa, como no daoísmo, pela participação no todo, quase mineralização, onde a impessoalidade não significa necessariamente despersonalização mas, pelo contrário, a formação de um ser outro, como a borboleta Aurelia dos neo-platónicos de Alexandria, símbolo de uma nova sabedoria.

Podemos concluir que o ateísmo de Camilo Pessanha não o conduziu a um beco sem saída, como o poema "Estátua" parecia anunciar. Pelo contrário, permitiu-lhe navegar por territórios desconhecidos, não se fechar na sua própria cultura e dotar a sua poesia de uma universalidade e de uma atemporalidade inegáveis.

Quando nos subtraímos a essa ideia em que tudo cabe e que tudo explica, ficamos sós perante o Cosmos, mas é precisamente nesse momento que se revelam a tragédia e a beleza da condição humana, desse animal cujo dever é olhar o universo de frente, sem improváveis mediações, assumindo-se como filho das estrelas e do mar, assombrado pela ideia de infinito e orgulhoso por ser uma pequena chama no vasto incêndio do universo.

\section{Referências}

Bachelard, Gaston. La dialectique de la durée. Paris: Puf, 2006. 
Dias Miguel, António. Camilo Pessanha: elementos para o estudo da sua biografia e a da sua obra. Edição de Álvaro Pinto (“Ocidente”). Lisboa, 1956.

Lemos, Ester de. A “Clépsidra” de Camilo Pessanha: notas e reflexões. Lisboa: Tavares Martins, 1956.

Nietzsche, Friederich. Genealogia da Moral. Lisboa: Guimarães Editores, 1983.

Novalis. Fragmentos, diálogos monólogos. São Paulo: Iluminuras, 2009.

Onfray, Michel. Tratado de Ateologia. Lisboa: Edições Asa, 2007 Rubim, Gustavo. Experiência da alucinação: Camilo Pessanha e a questão da poesia. Lisboa: Caminho, 1993.

José, Carlos Morais. A dor que deveras sente. In: Simas, Monica (Org.). Estudos sobre Macau e outros orientes. São Paulo: Paulistana, 2017. p. 260-279. 